\title{
Efficient modeling of a structure with friction dampers
}

\author{
Younghoo Choi, Hyungoo Kang, and Jinkoo Kim
}

\begin{abstract}
This study investigated the efficient modeling of a framed structure to be used for optimal distribution of friction dampers using genetic algorithm. As huge amount of nonlinear time history analysis of the structure was involved in the GA procedure, the model structure was transformed into a simplified 15 degrees of freedom system with similar dynamic characteristics. The range of friction damping effective in reducing earthquake response of the model structure was determined as a preliminary study for optimal damper distribution using an equivalent single degree of freedom system. Then the original model structure was transformed into equivalent multi-degrees of freedom system with one degree of freedom in each story to reduce the computation time required for nonlinear dynamic time history analyses. The pushover and the nonlinear dynamic analysis results of the ESDOF system and the original model structure show that the simplified modeling technique is valid.
\end{abstract}

Keywords-component; Seismic Retrofit, Friction dampers, Genetic algorithm, Optimal design, RC Moment Frames

\section{INTRODUCTION}

Many researchers have been investigated to find out efficient damper distribution techniques throughout the stories. For low-rise structures dominated primarily by the fundamental mode of vibration, simple intuitive methods for story-wise distribution of dampers may be applicable. However for medium to high-rise structures with strong participation of higher vibration modes, more sophisticated optimization algorithm for damper distribution is required. One of the efficient methods used for optimum design of structures is the genetic algorithm (GA), which is a robust optimization technique based on the principles of natural biological evolution. GA has been applied for optimum design of structures [1, 2] and Kargahi and Ekwueme [3] applied GA to calculate the optimum design parameters for viscous dampers to satisfy a pre-selected design objective.

In this study GA method was applied to optimum friction damper distribution in a 15-story reinforced concrete structure with relatively long fundamental natural period in its longitudinal direction to minimize seismic responses. As huge amount of nonlinear time history analysis of the structure was involved in the GA procedure, the model structure was transformed into a simplified 15 degrees of freedom system with similar dynamic characteristics.

Younghoo Choi, Hyungoo Kang, and Jinkoo Kim

Dept. Civil and Architectural Eng,

Korea

\section{NONLINEAR MODELING OF EXAMPLE STRUCTURE}

The analysis model structure to be retrofitted with friction dampers is a 15-story reinforced concrete building. The structure is composed of moment resisting frames in both directions and has uniform story height of $2.65 \mathrm{~m}$. The structure has a rectangular plan shape with $5 \mathrm{~m}$ span length along the longitudinal direction and $3.35 \mathrm{~m}$ and $3.55 \mathrm{~m}$ span length along the transverse direction as shown in Fig. 1.

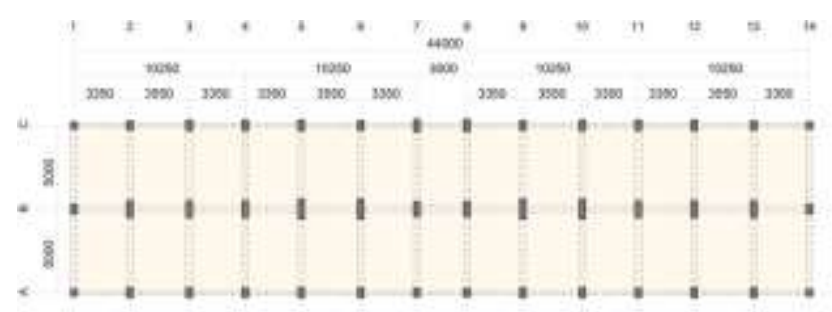

(a) Structural plan

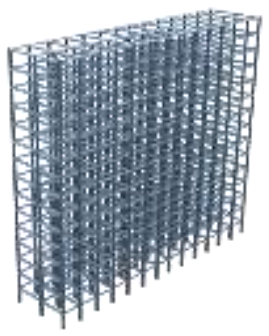

(b) 3D view

Fig. 1 Configuration of the 15-story model structure

Nonlinear static analysis was carried out using the program code Perform 3-D [4]. The nonlinear bending moment vs. rotation relationships of beams and columns were represented by tri-linear lines as shown in Fig. 2.

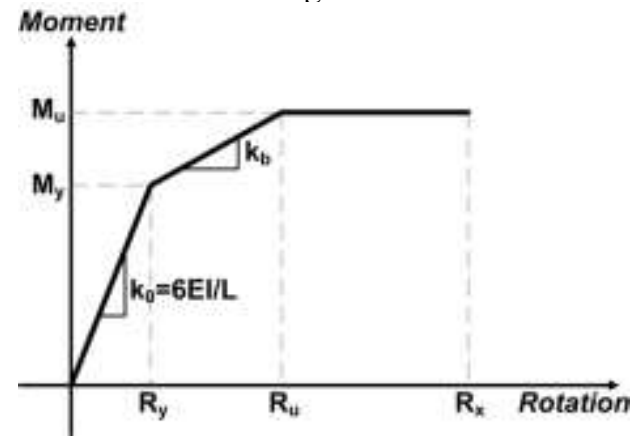

Fig. 2 Nonlinear bending moment - chord rotation model of beams and columns 
The nonlinear bending moment vs. rotation relationships of beams and columns were represented by tri-linear lines as shown in Fig. 2. The post yield stiffness varies depending on the axial force as specified in the ASCE/SEI 41-06 [5]. Following the recommendation of ASCE/SEI 41-06, the overstrength factors of 1.5 and 1.25 were applied for the strength of reinforced concrete and re-bars, respectively. The effective stiffness of beams and columns in elastic range was reduced considering cracked section.

Pushover analyses were carried out along the longitudinal and the transverse directions using lateral load proportional to the fundamental mode shape of the structure in each direction. The lateral loads were applied until the roof displacements reached $4 \%$ of the building height, and the base shear vs. roof displacement curves were plotted in Fig. 3. The points corresponding to the design base shear, yield point, and the maximum inter-story drift of $2 \%$ are indicated on the pushover curves. The design base shears were obtained from ASCE 7-10 [6] using the design spectral acceleration coefficients $S_{D S}=0.49$ and $S_{D 1}=0.28$. It can be observed that the strength along the longitudinal direction is significantly smaller than the strength along the transverse direction, even smaller than the design base shear. This is due to the fact that the design wind load along the transverse direction is much higher than that along the longitudinal direction, and the seismic load was not considered in the design. It was observed that, when loaded along the longitudinal direction, plastic hinges first formed at the beams in the mid height and subsequently spread throughout the stories. The strength rapidly decreased when plastic hinges formed at the columns in the tenth and eleventh stories. Based on the pushover analysis results it was concluded that the model structure, which was designed without consideration of seismic load, needed seismic retrofit along the longitudinal direction.

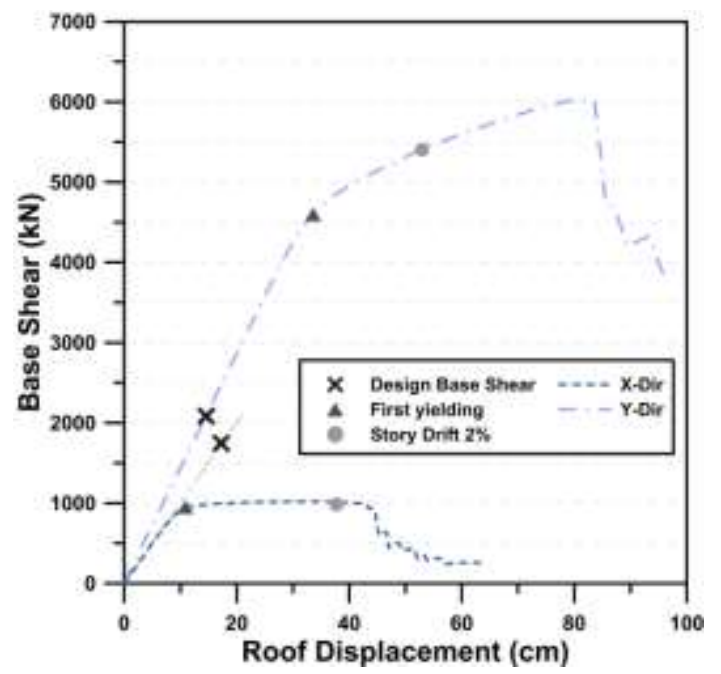

Fig. 3 Nonlinear static pushover analysis result of the model structure

\section{SIMPLIFIED MODELING OF EXAMPLE STRUCTURE}

In this study the optimum story-wise distribution of damper slip force to minimize structural responses was considered as the main design variable to be optimized using genetic algorithm. It was assumed that the dampers were installed along the longitudinal direction at locations where they did not affect the symmetry of the structure. Since huge number of nonlinear time history analyses were involved in the optimization process using GA, the use of the 15-story full scale model structure was almost impossible. To reduce the computation time significantly, the model structure was transformed into an equivalent 15 degrees of freedom system as shown in Fig. 4. The stiffness of each story of the equivalent structure was obtained from the story shear vs. inter-story drift relationships of the original structure shown in Fig. 5..

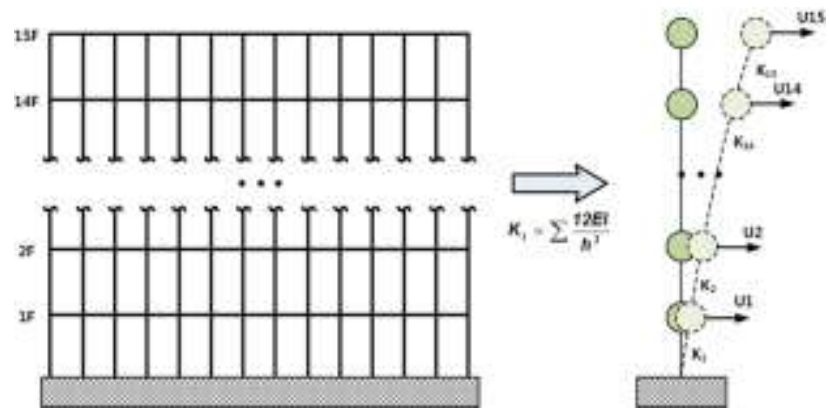

Fig. 4 15-degrees of freedom system idealization of the model structure

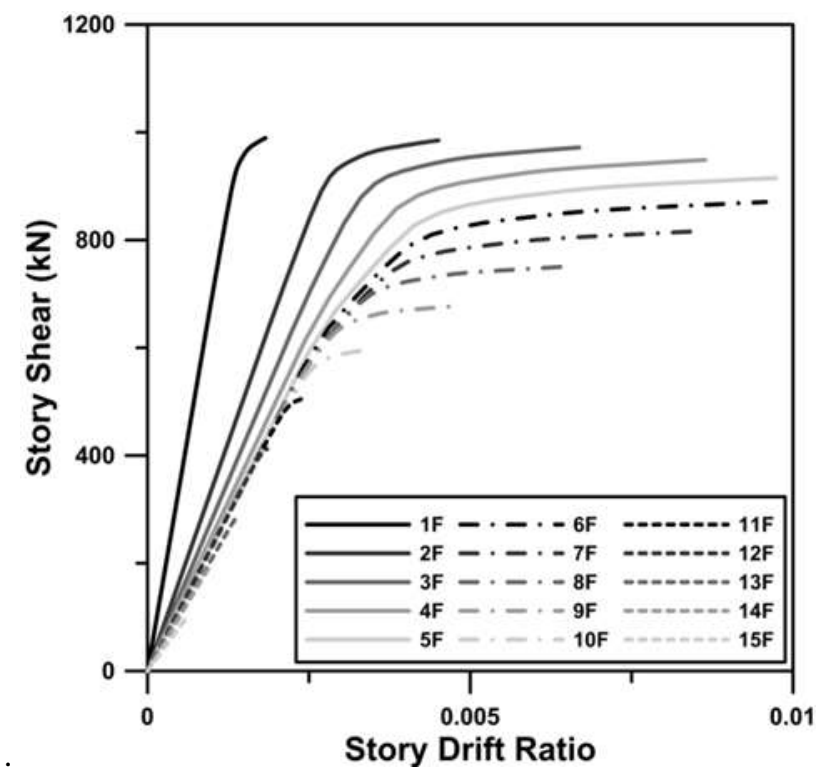

Fig. 5 Story stiffness of the model structure obtained from pushover analysis 
ISBN: 978-1-63248-074-3 doi: 10.15224/ 978-1-63248-074-3-31

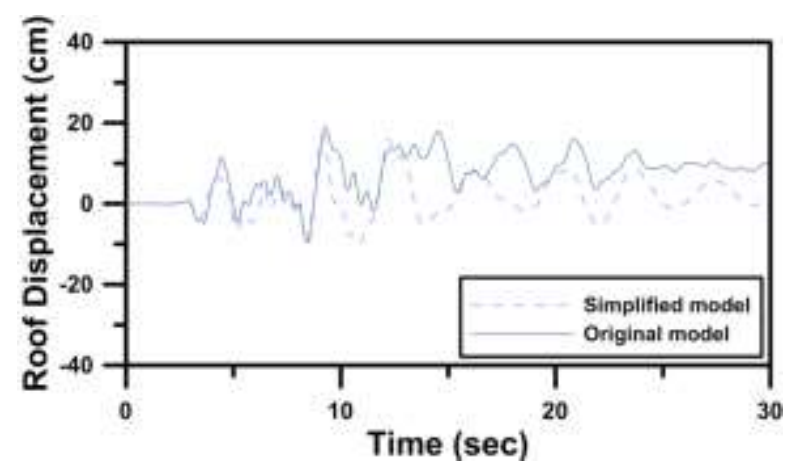

Fig. 6 Comparison of roof displacement time histories of original and simplified models (Northridge earthquake, $\mathrm{PGA}=0.52 \mathrm{~g}$ )

Fig. 6 shows the roof displacement time histories of the original and the simplified models obtained from the nonlinear time history analysis using the Northridge earthquake $(\mathrm{PGA}=0.52 \mathrm{~g})$. Even though the two results are not identical, the simplified model represents the maximum value reasonably well.

\section{DETERMINATION OF EFFECTIVE FRICTION DAMPING}

In this section the range of friction damping effective in reducing earthquake response of the model structure was determined as a preliminary study for optimal damper distribution. To reduce the computation time required for nonlinear dynamic analysis, parametric study was carried out using an equivalent single degree of freedom (ESDOF) system derived from the original structure using the following formulation:

$$
M_{l}^{*}=\frac{\left(\sum_{j=1}^{n} m_{j} \varphi_{j l}\right)^{2}}{\sum_{j=1}^{n} m_{j} \varphi_{j l}^{2}} \quad T_{e f f}=2 \pi \sqrt{\frac{S_{d}}{S_{a} g}}
$$

where $M_{1}^{*}$ is the effective modal pass, $\mathrm{m}_{\mathrm{j}}$ and $\varphi_{j 1}$ are the mass and the mode shape coefficient of the $j^{\text {th }}$ story, $S_{d}$ and $S_{a}$ are the spectral displacement and acceleration corresponding to the fundamental mode of vibration, and $T_{\text {eff }}$ is the effective natural period of the first mode of vibration. The effective stiffness can be obtained from the above equation. Fig. 7 depicts the idealized modeling and the force-displacement relationship of the equivalent system with a damper used in the analysis. In the modeling of the damper $\mathrm{f}_{\mathrm{s}}$ is the slip force of the friction damper and $\mathrm{k}_{\mathrm{b}}$ is the stiffness of the connecting brace. The initial stiffness is contributed from the combined action of the structure and the damper, while only the structure resists the additional load after yielding of the friction damper. The pushover curve of the ESDOF system is compared with that of the original model structure in Fig. 8, where it can be found that the two curves match reasonably well considering the simplicity of the ESDOF model. To confirm the validity of the ESDOF system, nonlinear dynamic analyses of the original and the ESDOF system were carried out using the Superstition Hills earthquake record selected from the data base provided in the Pacific Earthquake Engineering Research (PEER) Center. Fig. 12 compares the top-story displacement time histories of the original and the ESDOF system obtained from the analysis, where it can be observed that the two responses generally coincide well with each other in terms of the maximum values. The parametric study also showed that the maximum displacement decreased significantly as the friction force exceeded $10 \%$ of the design base shear. When the stiffness of the connecting braces increased the mean maximum displacement of the system decreased and the dissipated energy increased. The figure shows that when the stiffness of the connecting braces is twice the system stiffness, the displacement response is the minimum in case the slip force is about $25 \%$ of the design base shear. Also the total dissipated energy is highest when the slip force is between 10 to $25 \%$ of the base shear. It was observed that as the stiffness of the connecting braces further increased more than twice the stiffness of the structure the decrease in the maximum displacement and the increase in the dissipated energy was only marginal. Based on the parametric study presented in this section, the total damping force was restricted within and the stiffness of the connecting braces was kept twice of the story stiffness in the following optimization process for dampers.

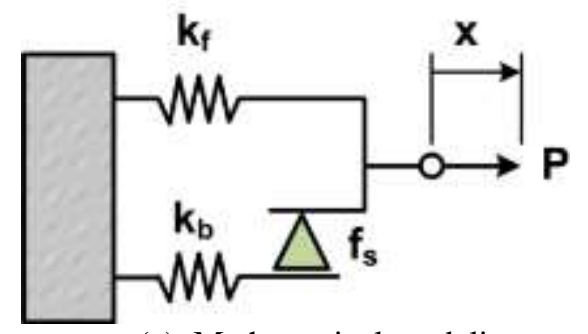

(a) Mathematical modeling

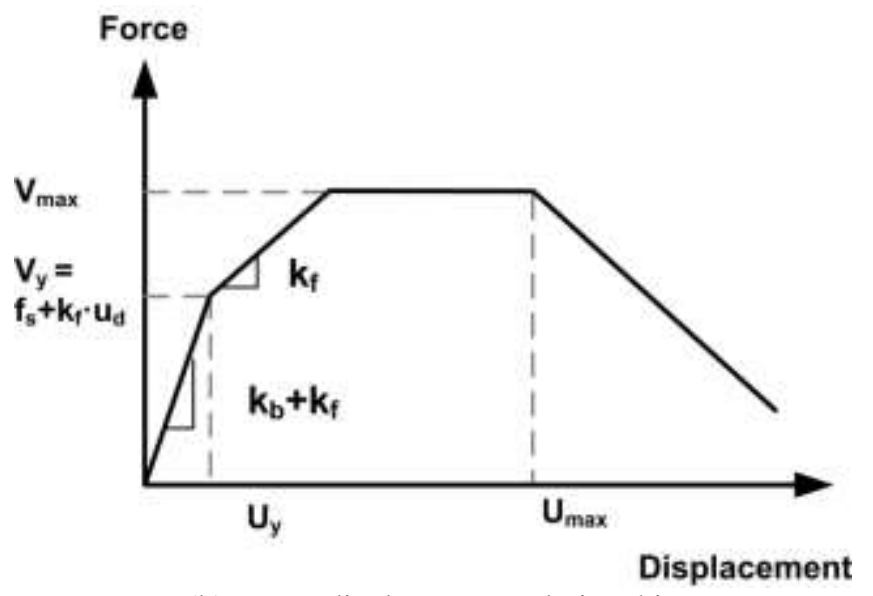

(b) Force-displacement relationship

Fig. 7 Modeling of the ESDOF structure with friction damper 


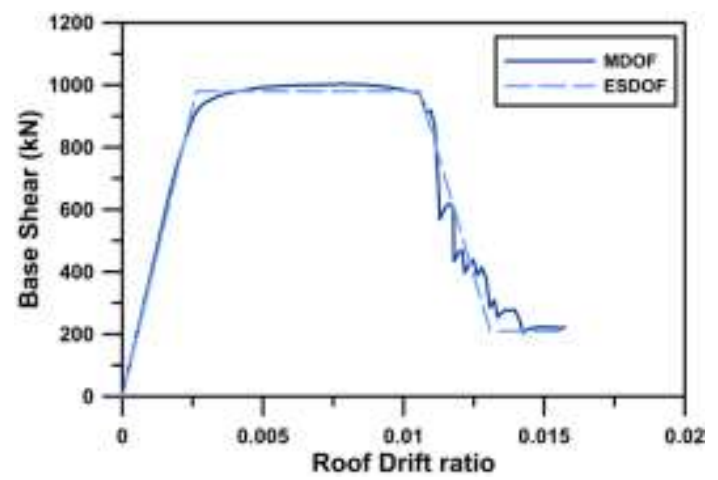

Fig. 8 Nonlinear force-displacement curves of the original and the ESDOF system

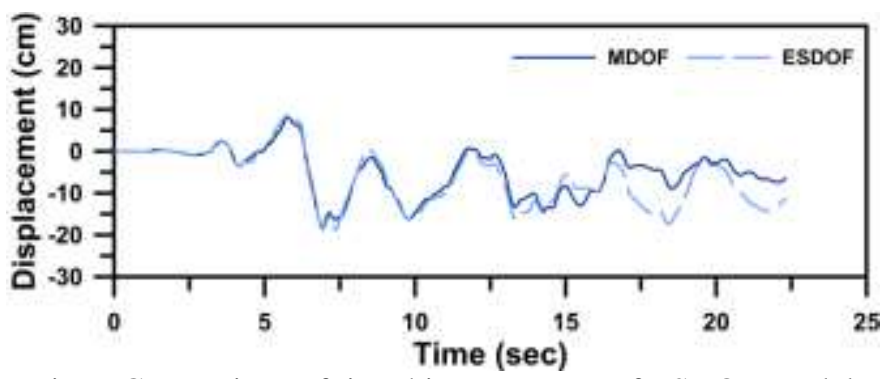

Fig. 9 Comparison of time history curves of ESDOF model and MDOF model for Superstition Hills EQ

\section{SUMMARY}

This study investigated the efficient modeling of a framed structure to be used for optimal distribution of friction dampers using genetic algorithm. As huge amount of nonlinear time history analysis of the structure was involved in the GA procedure, the model structure was transformed into a simplified 15 degrees of freedom system with similar dynamic characteristics. The range of friction damping effective in reducing earthquake response of the model structure was determined as a preliminary study for optimal damper distribution using an equivalent single degree of freedom system. Then the original model structure was transformed into equivalent multi-degrees of freedom system with one degree of freedom in each story to reduce the computation time required for nonlinear dynamic time history analyses. The pushover and the nonlinear dynamic analysis results of the ESDOF system and the original model structure show that the simplified modeling technique is valid.

\section{ACKNOWLEDGMENT}

This research was supported by a grant (13AUDPB066083-01) from Architecture \& Urban Development Research Program funded by Ministry of Land, Infrastructure and Transport of Korean government.

\section{REFERENCES}

[1] Rajeev S, Krishnamoorthy CS. 1997, Genetic algorithm based methodologies for design optimization of trusses, Engineering Structures, $123,350-358$

[2] Hultman M. (2010), Weight optimization of steel trusses by a genetic algorithm - Size, shape and topology optimization according to Eurocode, Master's thesis, Department of Structural Engineering, Lund Institute of Technology.

[3] Kargahi, M. and Ekwueme, C. (2009) Structural Optimization of Viscous Dampers Using Genetic Algorithms for Improving Seismic Performance of Existing Buildings.: pp. 955-966..

[4] PERFORM-3D. Nonlinear analysis and Performance Assessment for 3D Structures-User Guide. Berkeley (CA, USA): Computers and Structures; 2006..

[5] ASCE 41 (2006). Seismic Rehabilitation of Existing Buildinigs. American Society of Civil Engineers

[6] ASCE 7 (2010). Minimum Design Loads for Buildings and Other Strucutres. American Society of Civil Engineers. 